\title{
Dural carotid-cavernous fistulas: our experience with endovascular management
}

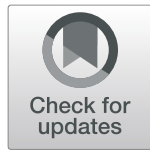

\author{
Surya Nandan Prasad ${ }^{1}$ (D, Alok Pratap Singh ${ }^{2}$, Vikas Kanaujia ${ }^{2}$, Vivek Singh ${ }^{1^{*}}$ (D) Rajendra Vishnu Phadke ${ }^{3}$ and \\ Kumudini Sharma ${ }^{2}$
}

\begin{abstract}
Background: Indirect carotid-cavernous fistulas (CCF) are dural arteriovenous fistula of the cavernous sinus and generally present with ocular symptoms. High index of clinical suspicion and radiological work up is required for diagnosis, and treatment is primarily endovascular embolization. We present our experience in diagnosis and management of indirect CCF along with technical evolution to perform embolization and different vascular accesses for difficult anatomy.
\end{abstract}

Results: Among a total of 20 indirect CCF cases who were treated with embolization in our department from 2013 to 2020 , five (25\%) were type C and 15 (75\%) were type D. Seven were treated with trans-arterial access only, 11 were treated by transvenous access only, and two were treated by taking both transvenous and trans-arterial access. No recurrence was seen in angiographically cured patients. Out of seven patients who suffered various grades of visual deficit, five recovered completely and two had fixed visual deficit. Third and sixth cranial nerve palsy persisted in two patients even after CCF embolization.

Conclusion: Indirect CCF is a treatable cause of troublesome ocular symptoms. Endovascular embolization is preferred treatment with excellent short- and long-term outcome. The embolization becomes difficult and challenging in cases where the conventional vascular access to the cavernous sinus is occluded.

Keywords: Dural fistula, Indirect CCF, Proptosis, Endovascular embolization, Chemosis

\section{Background}

Carotid-cavernous fistula (CCF) is characterized by abnormal fistulous connection between carotid arterial system (internal carotid artery (ICA), external carotid artery (ECA), or both) and cavernous sinus. They are classified as direct (type A) and indirect (type B, C, and D) types. Direct or type A CCF is characterized by direct fistulous connection between cavernous segment of ICA and cavernous sinus. Majority ( 85\%) of type A CCF are posttraumatic, and among non-traumatic cases, most of them result from spontaneous rupture of pre-existing ICA aneurysm into the cavernous sinus [1-3].

\footnotetext{
* Correspondence: singhvivek79@rediffmail.com

'Department of Radiodiagnosis, Sanjay Gandhi Post Graduate Institute of Medical Sciences, Lucknow, India

Full list of author information is available at the end of the article
}

Indirect carotid-cavernous fistula is also known as dural fistula of cavernous sinus. They are a special type of dural arteriovenous fistula where the immediate venous drainage is into the cavernous sinus. Based on angioarchitecture, they are further classified into type B (fistulous connection between dural branches of ICA with cavernous sinus), type $C$ (fistulous connection between dural branches of ECA with cavernous sinus), and type D (fistulous connection between dural branches of both ICA and ECA with cavernous sinus). Among different types of indirect CCF, type B is the least common and type $\mathrm{D}$ is the most common variety found in clinical practice.

Indirect CCF are low flow dural fistulas and mostly have protracted clinical course. The patients usually present with chronic eye congestion, variable degree of proptosis, headache, and orbital bruit either uni- or

\section{Springer Open}

(๑) The Author(s). 2021 Open Access This article is licensed under a Creative Commons Attribution 4.0 International License, which permits use, sharing, adaptation, distribution and reproduction in any medium or format, as long as you give appropriate credit to the original author(s) and the source, provide a link to the Creative Commons licence, and indicate if changes were made. The images or other third party material in this article are included in the article's Creative Commons licence, unless indicated otherwise in a credit line to the material. If material is not included in the article's Creative Commons licence and your intended use is not permitted by statutory regulation or exceeds the permitted use, you will need to obtain permission directly from the copyright holder. To view a copy of this licence, visit http://creativecommons.org/licenses/by/4.0/. 
bilaterally depending upon the sub types and predominant venous drainage of the fistula [4-6]. Knowledge of pathophysiology of indirect CCF and a high degree of clinical suspicion is required to make an early diagnosis of this disease. Delay in diagnosis and treatment may result in various grades of visual deficits or even loss of vision. They are treated primarily by endovascular methods with preferred transvenous access.

\section{Methods}

A retrospective analysis was done of all the cases of indirect CCF which were managed by endovascular methods in our department from 2013 to 2020. Clinical signs and symptoms, history of trauma, duration of symptoms, and demographic details at the time of presentation were recorded. Clinical and baseline ophthalmological evaluation was performed by an ophthalmologist. The diagnostic work up included cross-sectional imaging like contrast-enhanced computed tomography (CECT) or magnetic resonance imaging (MRI) followed by digital subtraction angiography (DSA) evaluation (Fig. 1). Then, endovascular embolization of the CCF was performed using coils and/ or liquid/particle embolic agents depending upon availability, patient's affordability, type of fistula, and ease of use. Post-procedure, the patients were followed-up clinically for improvement of symptoms at 1 week, 3 month, and 6 month intervals. Cases of residue were taken for re-embolization and then followed-up similarly.

\section{Results}

Total 20 cases (12 males, 8 females) of indirect CCF were included in the study, among which five $(25 \%)$ were type $\mathrm{C}$ and 15 (75\%) were type D (Table 1$)$. We did not find any type B CCF in our study. Average age of presentation was 39.33 years for males and 42.75 years for females. Average duration of presence of symptoms was 8.5 months. Eight of our patients were hypertensive and four of them also had diabetes mellitus.

Seven patients (including three type $\mathrm{C}$ and four type $\mathrm{D}$ CCF) were treated with trans-arterial access only, using PVA (poly-vinyl alcohol) particles (Fig. 2)/coils/liquid embolic agents (Fig. 3). In one case of type D CCF where the patient had history of trauma, we had to perform parent artery occlusion with detachable coils as the ICA was very tortuous and there was severe venous ectasia of cavernous sinus. In this case, adequacy of the intracranial circulation was assessed with pre procedure balloon occlusion test, which the patient tolerated well. In other three cases of type D CCF, the trans-arterial route was taken after failed attempts of transvenous cannulation.

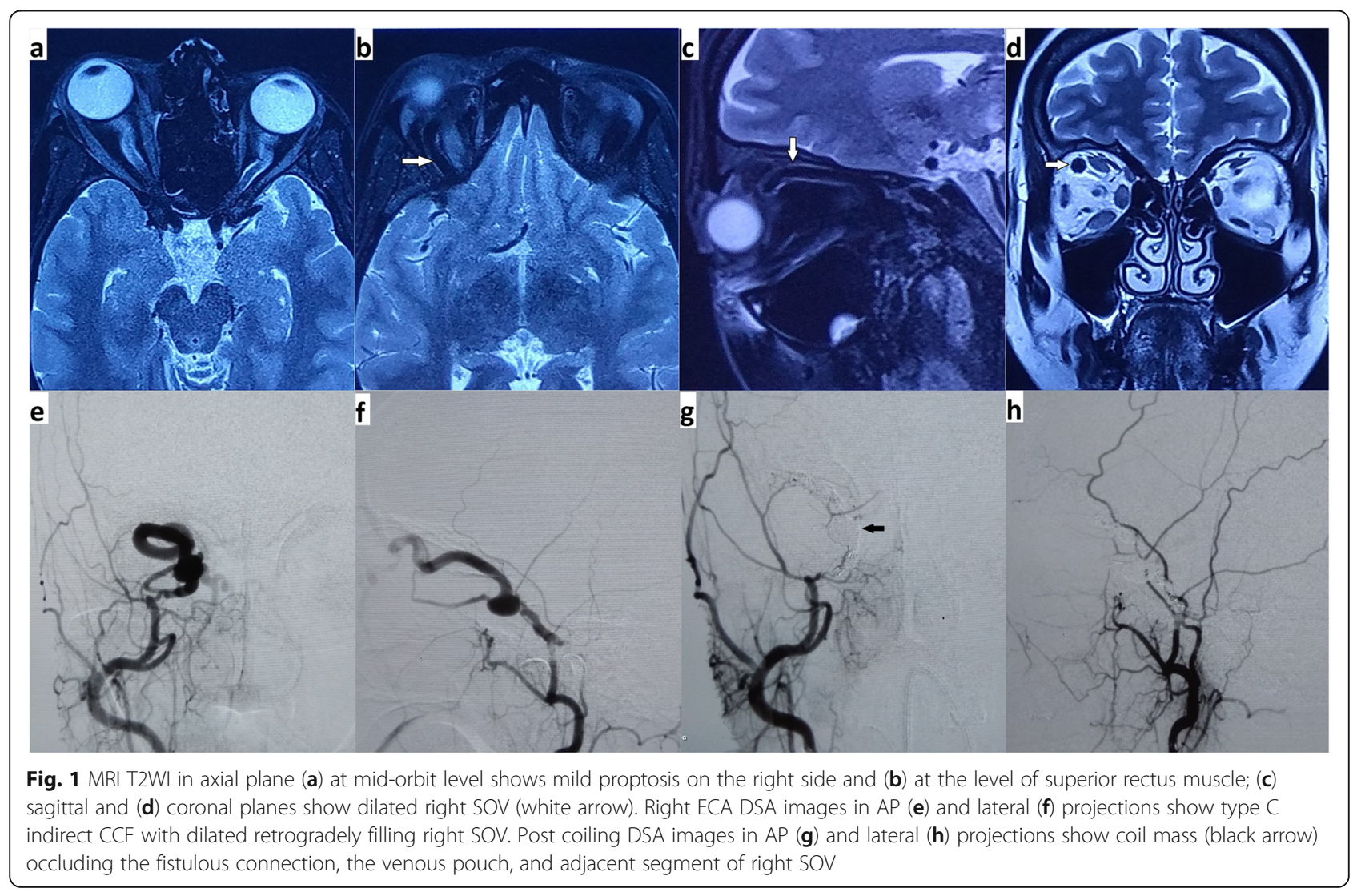


Table 1 Indirect CCF cases

\begin{tabular}{|c|c|c|c|c|c|c|c|c|c|c|}
\hline $\begin{array}{l}\mathrm{Sr} \\
\text { No. }\end{array}$ & $\begin{array}{l}\text { Age/ } \\
\text { sex }\end{array}$ & Presentation & Comorbidities & $\begin{array}{l}\text { Duration } \\
\text { (months) }\end{array}$ & Side & Type & Approach & Material used & Session & $\begin{array}{l}\text { Post-procedure status/ } \\
\text { follow-up }\end{array}$ \\
\hline 1. & $60 / M$ & $\begin{array}{l}\text { Chemosis, } \\
\text { proptosis, diplopia }\end{array}$ & HTN, DM & 4 & Right & C & TAE & PVA & 1 & Improved \\
\hline 2. & $35 / F$ & $\begin{array}{l}\text { Chemosis, } \\
\text { proptosis, } \downarrow \text { vision }\end{array}$ & - & 6 & Left & C & TAE & $\begin{array}{l}\text { Detachable } \\
\text { coils, n-BCA }\end{array}$ & 1 & Improved \\
\hline 3. & $42 / \mathrm{M}$ & $\begin{array}{l}\text { B/l chemosis, } \\
\text { proptosis, diplopia }\end{array}$ & HTN & 12 & Left & $D$ & TVE-IPS & Detachable coils & 1 & $\begin{array}{l}\text { Improved, persistent 3rd } \\
\text { and 6th CN palsy }\end{array}$ \\
\hline 4. & $49 / F$ & Chemosis, proptosis & HTN, DM & 6 & Right & $D$ & TAE & PVA & 2 & Improved \\
\hline 5. & 18/M & $\begin{array}{l}\text { RTA, proptosis, } \\
\text { chemosis, } \downarrow \text { vision }\end{array}$ & - & 16 & Right & $D$ & TAE & PVA & 2 & Improved \\
\hline 6. & $42 / F$ & $\begin{array}{l}\text { Chemosis, } \\
\text { proptosis, diplopia }\end{array}$ & - & 9 & Left & $\mathrm{D}$ & TVE-IJV-FV & Detachable coils & 1 & Improved \\
\hline 7. & $70 / F$ & Chemosis, proptosis & HTN, DM & 11 & Left & $D$ & TAE & PVA & 1 & Improved \\
\hline 8. & $34 / \mathrm{M}$ & $\begin{array}{l}\text { RTA, chemosis, } \\
\text { proptosis, } \downarrow \text { vision }\end{array}$ & - & 2 & Left & $\mathrm{D}$ & TAE-PAO & Detachable coils & 1 & $\begin{array}{l}\text { Improved, persistent 3rd } \\
\text { and 6th CN palsy }\end{array}$ \\
\hline 9. & $42 / F$ & Chemosis, proptosis & HTN, DM, CVST & 8 & Left & $D$ & TVE-IPS & Fibred coils & 1 & Improved \\
\hline 10. & $40 / F$ & Chemosis, proptosis & CTD & 6 & Right & D & TVE/TAE & $\begin{array}{l}\text { Detachable } \\
\text { coils, PVA }\end{array}$ & 1 & Improved \\
\hline 11. & $41 / \mathrm{M}$ & $\begin{array}{l}\text { Chemosis, } \\
\text { proptosis, diplopia }\end{array}$ & - & 7 & Right & $\mathrm{D}$ & TVE/TAE & $\begin{array}{l}\text { Detachable } \\
\text { coils, PVA }\end{array}$ & 1 & Improved \\
\hline 12. & $57 / M$ & $\begin{array}{l}\text { B/I chemosis, } \\
\text { proptosis, } \downarrow \text { vision }\end{array}$ & HTN & 6 & Left & $C$ & $\begin{array}{l}\text { TVE-direct FV } \\
\text { puncture }\end{array}$ & Fibred coils & 1 & Improved \\
\hline 13. & $49 / M$ & $\begin{array}{l}\text { Chemosis, } \\
\text { proptosis, diplopia }\end{array}$ & - & 5 & Left & $D$ & TVE-IPS & Fibred coils & 1 & Improved \\
\hline 14. & $50 / \mathrm{M}$ & $\begin{array}{l}\text { B/l proptosis, } \\
\text { chemosis }\end{array}$ & HTN & 6 & Left & $\mathrm{D}$ & TVE-IPS & Fibred coils & 1 & Improved \\
\hline 15. & $17 / M$ & $\begin{array}{l}\text { Chemosis, } \\
\text { proptosis, } \downarrow \text { vision }\end{array}$ & - & 3 & Right & D & TVE-IPS & Fibred coils & 1 & Improved \\
\hline 16. & $47 / M$ & $\begin{array}{l}\text { Chemosis, } \\
\text { proptosis, diplopia }\end{array}$ & HTN & 9 & Right & D & TVE-IPS & Fibred coils & 1 & Improved \\
\hline 17. & $37 / M$ & $\begin{array}{l}\text { Chemosis, } \\
\text { proptosis, } \downarrow \text { vision }\end{array}$ & - & 15 & Right & $D$ & TVE-IPS & Fibred coils & 1 & $\begin{array}{l}\text { Improved, persistent } \\
\downarrow \text { \vision }\end{array}$ \\
\hline 18. & 20/M & $\begin{array}{l}\text { Proptosis, vision } \\
\text { loss }\end{array}$ & - & 18 & Right & C & TVE-IPS & Fibred coils & 1 & $\begin{array}{l}\text { Proptosis decreased, } \\
\text { vision loss persisted }\end{array}$ \\
\hline 19. & $31 / F$ & $\begin{array}{l}\text { Chemosis, } \\
\text { proptosis, diplopia }\end{array}$ & - & 14 & Right & C & TAE & $\begin{array}{l}\text { Fibred coils, n- } \\
\text { BCA }\end{array}$ & 1 & Improved \\
\hline 20. & $33 / F$ & Chemosis, proptosis & - & 7 & Right & C & TVE-IPS & Fibred coils & 1 & Improved \\
\hline
\end{tabular}

Abbreviations: $M$ male, $F=$ female, $H T N$ hypertension, DM diabetes mellitus, TAE trans-arterial embolization, $P V A$ poly-vinyl alcohol particles, $n$ - $B C A$ N butyl cyanoacrylate (glue), $B / /$ bilateral, TVE transvenous embolization, IPS inferior petrosal sinus, $C N$ cranial nerve, RTA road traffic accident, IJV internal jugular vein, FV facial vein, PAO parent artery occlusion, CVST cerebral venous sinus thrombosis, CTD connective tissue disorder

Total 11 cases were treated by transvenous access only, using coils (Tables 2 and 3). In the transvenous group, inferior petrosal sinus (IPS) route was used to access ipsilateral cavernous sinus in 9 cases (Fig. 4). In one case, where the inferior petrosal sinus was completely occluded and replaced by collaterals, we accessed the cavernous sinus after ultrasound (USG)-guided direct puncture of the ipsilateral facial vein (Fig. 5). In one other similar case, we successfully recanalized the occluded IPS by the microwire and managed to cannulate the ipsilateral cavernous sinus through the IPS (Fig. 6).
In one other case of occluded IPS, the attempted recanalization of IPS failed and the involved cavernous sinus could not be reached from the opposite side through trans-cavernous connections. In this case, the microcatheter was passed from the jugular vein to a small tributary of ipsilateral facial vein and then the involved cavernous sinus was cannulated and coiled.

Two type $\mathrm{D}$ cases were treated with combined approach using both transvenous and trans-arterial access, as the CCF were showing residual filling from ECA branches after coil embolization through transvenous route. 


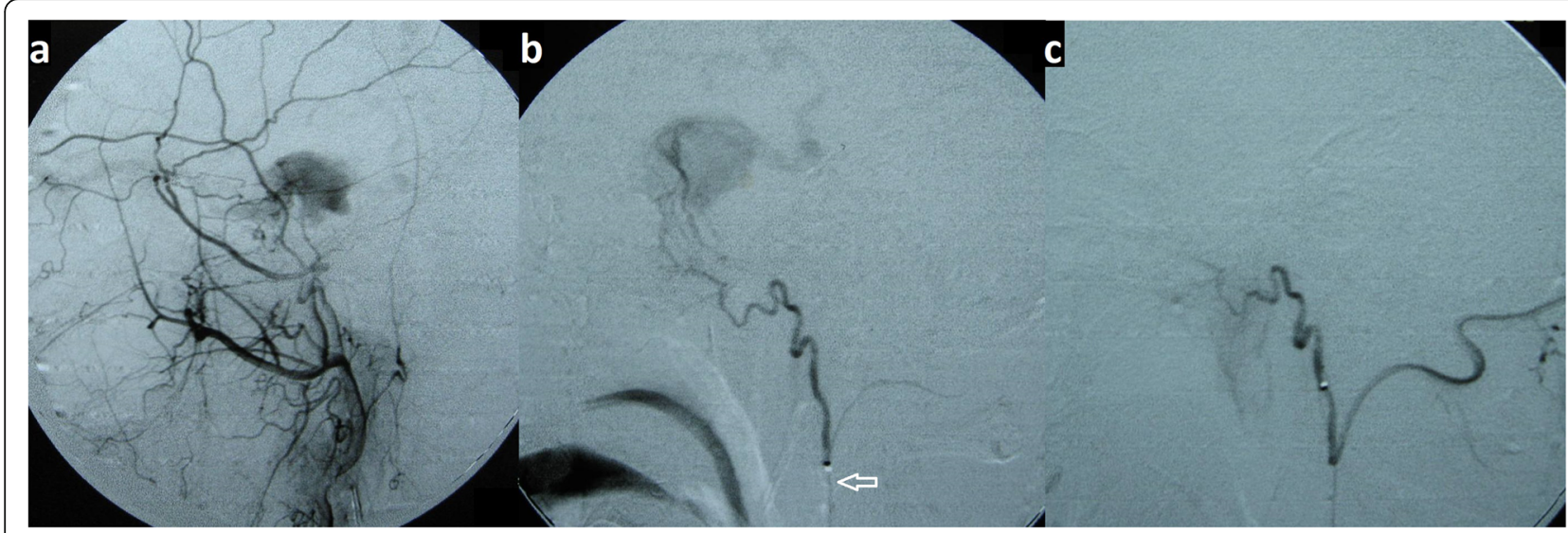

Fig. 2 a Right ECA DSA in lateral projection show type C indirect CCF with opacification of right cavernous sinus in arterial phase. b Selective cannulation of the feeding artery with microcatheter (arrow) for embolization with PVA particles. c Post embolization DSA shows non-filling of the fistula

Angiographically cured patients did not show any recurrence of initial symptoms on follow-up at 1-week, 1month, and 6-month intervals. Six patients had headache and diplopia on looking laterally to the extreme. Out of seven patients who suffered various grades of visual deficit, five recovered completely and two had persistent fixed visual deficit. Third and sixth cranial nerves palsy was present in two patients at the time of diagnosis and persisted even after coil embolization of the CCF.

\section{Discussion}

Barrow classified carotid-cavernous fistulas into direct (type A) and indirect (type B, C, and D) types based on angioarchitecture and the arterial feeder to the fistula [1,

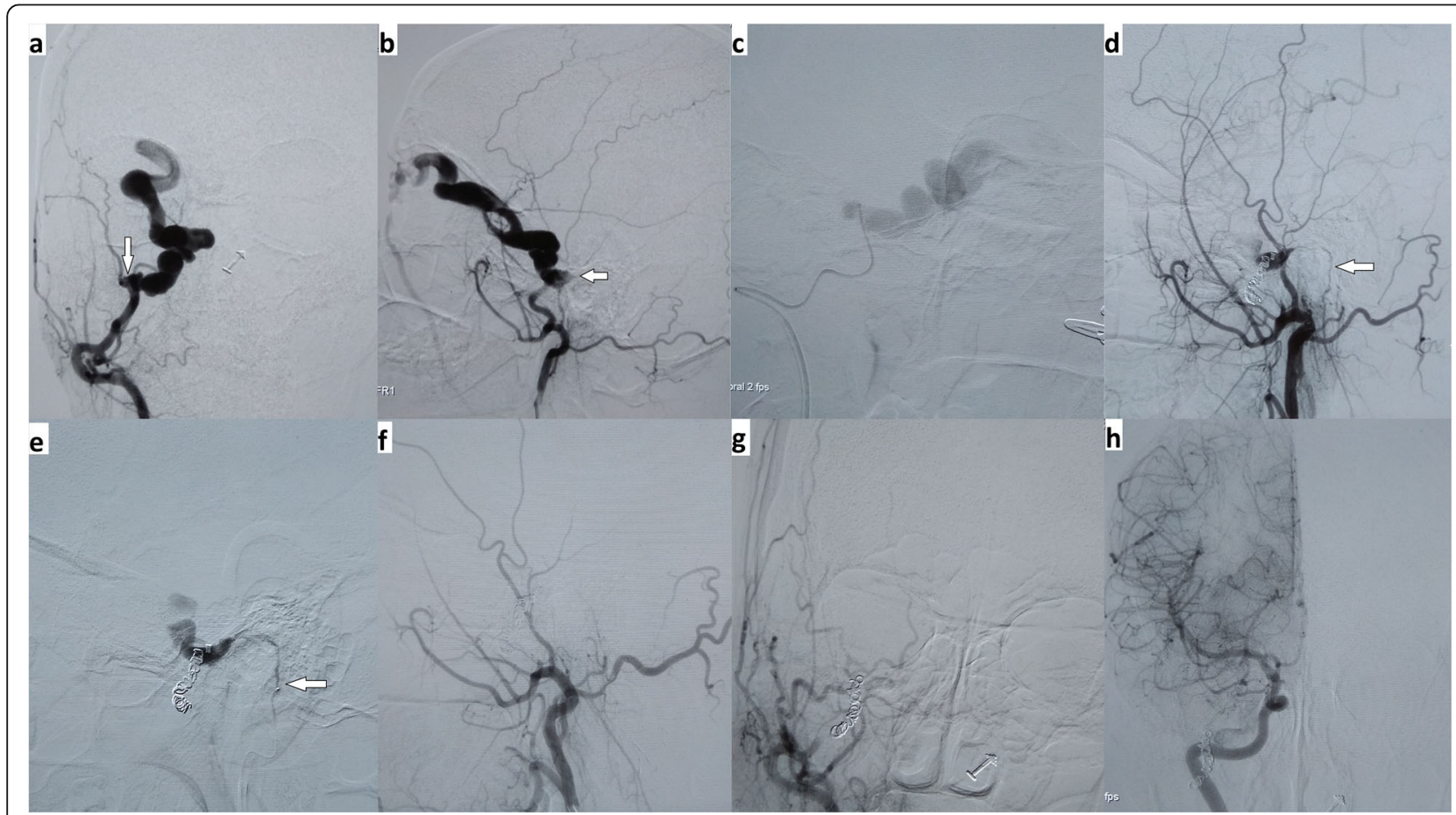

Fig. 3 DSA images in AP (a) and lateral (b) projections show type C indirect CCF with fistulous connection at foramen spinosum level (arrow). $\mathbf{c}$ Super-selective cannulation with tip of microcatheter at fistula site. $\mathbf{d}$ Post coiling DSA shows residual filling from a thin branch of the right occipital artery (arrow in $\mathbf{d}$ ). e Super-selective cannulation of the tiny feeder with another microcatheter (arrow in e). Post embolization DSA images in AP (f) and lateral (g) projections show non-filling of the fistula. $\mathbf{h}$ DSA image showing normal opacification of right ICA branches 
Table 2 Different approaches used for embolization

\begin{tabular}{ll}
\hline Route of embolization & Number of patients \\
\hline Arterial & 7 \\
Venous-patent IPS & 8 \\
Venous-recanalized IPS & 1 \\
Venous-facial vein & 2 \\
Arterial + venous & 2 \\
\hline
\end{tabular}

2, 6]. Indirect CCF are dural fistulas of cavernous sinus. Exact aetiology is not known; however, they are seen in association with chronic hypertension, diabetes mellitus, cavernous sinus thrombosis, collagen tissue disease, atherosclerosis, and trauma [3, 7]. Association with hypertension and diabetes mellitus was present in our series in a significant proportion of cases. Several authors have found its occurrence more in post-menopausal women; however, in our series among eight female patients, only two were of post-menopausal age [3, 5, 7]. Occurrence of the dural fistulas in infancy raises the possibility of congenital origin of this disease [3]. One type C CCF in our series had simultaneous presence of multiple vascular anomalies like congenital ipsilateral orbital capillary haemangioma, intracranial cavernoma, and developmental venous anomaly in brain parenchyma. The patient had complete vision loss and progressive increase in proptosis for 18 months. The possibility of congenital aetiology of indirect CCF cannot be ruled out in this case. Trauma is another less common cause of indirect CCF. In two of our cases, there was temporal association of the development of this disease with a prior trauma from road traffic accidents. In cases of single-hole dural fistulas, history of trauma should be specifically asked about [3].

Clinically indirect CCF have a subacute or chronic course and mostly present with chemosis, proptosis, diplopia, or vision disturbances [3-5, 7]. Sometimes ocular bruit may be present. The degree of symptoms vary and there may be intermittent remission and relapse of the symptoms due to re-routing of the venous drainage. Sometimes ocular symptoms may resolve because of spontaneous thrombosis of ophthalmic veins. These cases should be followed-up closely and further work up should be done to rule out the possibility of re-routing of venous drainage to more dangerous cortical or deep

Table 3 Embolizing agent used in managing these patients

\begin{tabular}{ll}
\hline Type of embolization agent used & Number of patients \\
\hline Non-fibred coils & 6 \\
Fibred coils & 10 \\
Only PVA & 4 \\
Combined (coil + PVA/liquid embolic agent) & 4 \\
\hline
\end{tabular}

cerebral veins, which put the patients at increased risk of intracranial haemorrhage or congestive brain pathologies $[3,7,8]$. Since this disease has a protracted clinical course and symptoms are largely non-specific, a high index of clinical suspicion is required to make an early diagnosis.

The natural course of indirect CCF is inconstant. The involved part of cavernous sinus may spontaneously thrombose resulting in resolution of the indirect $\mathrm{CCF}[3$, 7]. Alternatively, in a significant proportion of cases, the symptoms progress leading to increased ocular pressure, congestive changes, and decrease in vision. These cases need urgent treatment as delay may result in irreversible damage to the vision or persistent cranial nerve palsy. Two of our cases, who had symptoms for more than 12 months and decreased vision at the time of presentation, did not show improvement in vision. Similarly in two other cases, 3rd and 6th cranial nerve palsy persisted even after embolization of the CCF.

Initial diagnostic work up includes non-invasive crosssectional imaging with CT scan and MRI. Degree of proptosis, orbital oedema, engorged tortuous ophthalmic veins, and cavernous sinus enlargement are better depicted on MRI $[3,9]$. MRI also helps in evaluation of oedema and congestive brain parenchymal changes in cases where there is suspicion of re-routing of venous drainage. Cross-sectional imaging further helps to rule out other mimics like neoplasms and infective/inflammatory pathologies which may present with similar ocular symptoms [3]. Digital subtraction angiography (DSA) is the gold standard for diagnosis, flow dynamics evaluation and treatment planning of CCF $[4,9]$. DSA provides details of arterial feeders, site of fistulous connection, venous drainage pattern, venous re-routing, cortical venous reflux, and high-risk collaterals and in turn helps in determining the need of urgency of treatment $[3,4,6,7,9]$.

Treatment options include conservative management, surgical management, radiosurgery, and endovascular embolization [10]. When symptoms are mild and highrisk features are absent on diagnostic DSA, the patient may be put under conservative management with manual compression therapy. The manual compression therapy may result in closure of the fistula in up to $34 \%$ of cases as reported in literature by various authors $[3,5$, 7]. Surgery is not preferred and rarely performed. In the present era, the role of surgery is limited only to provide vascular access for endovascular management by surgically exposing ophthalmic veins, where other venous and arterial accesses had exhausted [3]. Stereotactic radiosurgery is another treatment method which appears effective; however, very delayed and variable response to treatment makes this therapy unsuitable for emergency cases $[9,11,12]$. 


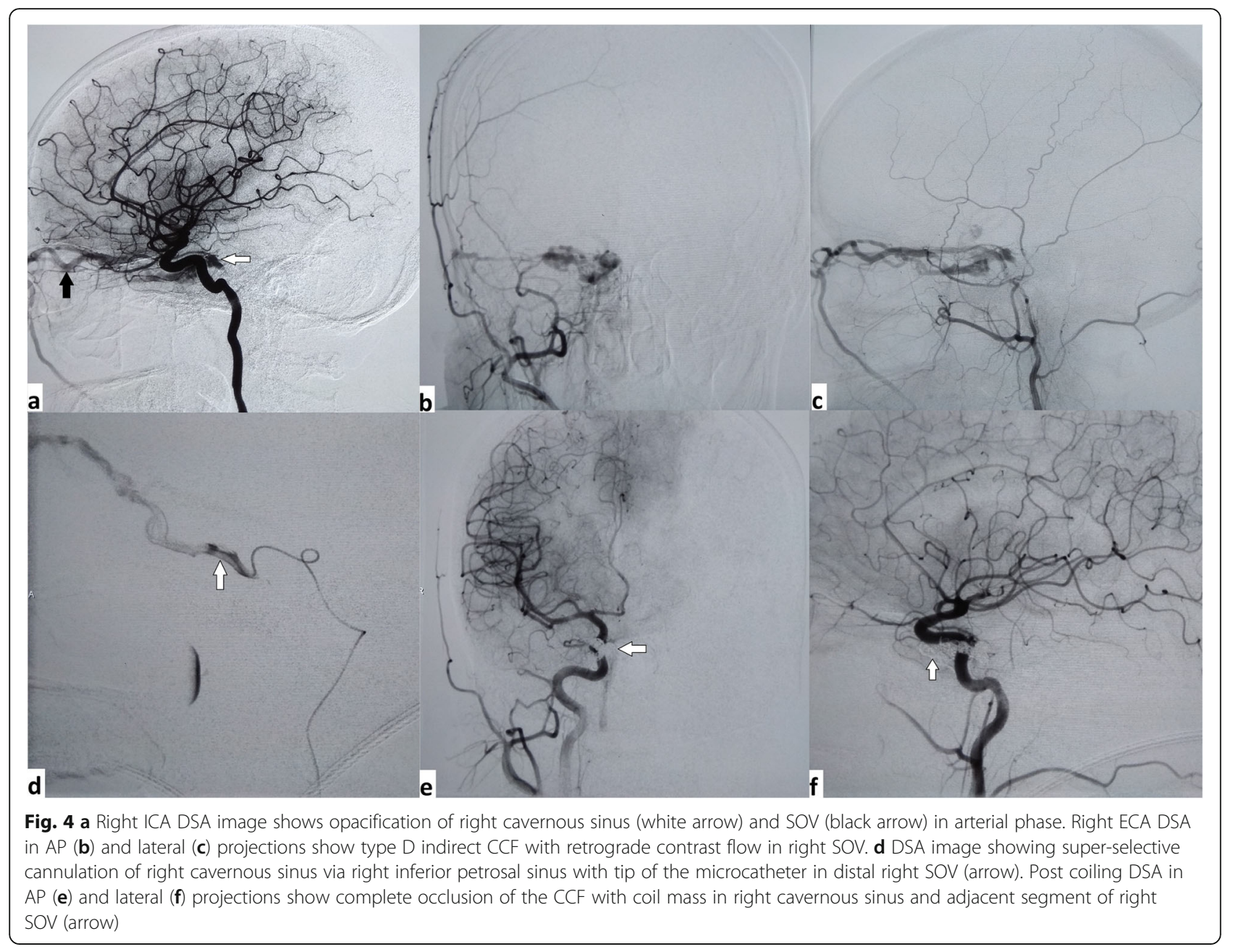

Endovascular management is the main stay of treatment in symptomatic patients and performed by taking transvenous or trans-arterial access [3, 9]. The principle of treatment in any dural fistula is closure of the fistulous connection as well as the immediate draining veins close to the fistula. Since the feeders in cases of indirect CCF are small calibre meningeal arteries, mostly it is not possible to occlude the venous drainage along with the fistulous connection while performing embolization through the arterial route [13]. The delivery of embolization materials at the site of fistula and into the immediate draining vein is best achieved through transvenous access in dural type CCF. In a standard procedure, transvenous access is obtained through femoral vein puncture. After putting the vascular sheath, a guide/ diagnostic catheter is advanced into the internal jugular vein and then ipsilateral inferior petrosal sinus (IPS) is super-selectively cannulated with a microcatheter to reach the involved cavernous sinus. Then, multiple coils are deployed to occlude the cavernous sinus near the fistula site. We used both bare platinum as well as fibred coils for embolization of the fistula. Complete closure of the CCF is ensured by taking in between angiograms by another diagnostic catheter already placed in the ECA of the side of the fistula. In 11 cases, where we treated the indirect CCF by taking transvenous access, the procedure was done in a single session and none of them showed recurrence or residual filling of the fistula.

In cases where the IPS is occluded or could not be cannulated due to difficult anatomy and collateralization, other alternative venous access has to be taken to reach the cavernous sinus [14]. Major alternative route targets the superior ophthalmic vein and its drainage territory into facial vein. USG-guided percutaneous puncture of the facial vein, direct puncture of ophthalmic vein with or without surgical exposure of the same, and even direct cavernous sinus puncture based on anatomic landmarks and with certain manoeuvres are described in literature [5, 13-18]. Cases are reported in literature where the interventionists have successfully cannulated the cavernous sinus through unconventional routes like via superior petrosal sinus or basal venous plexus and 


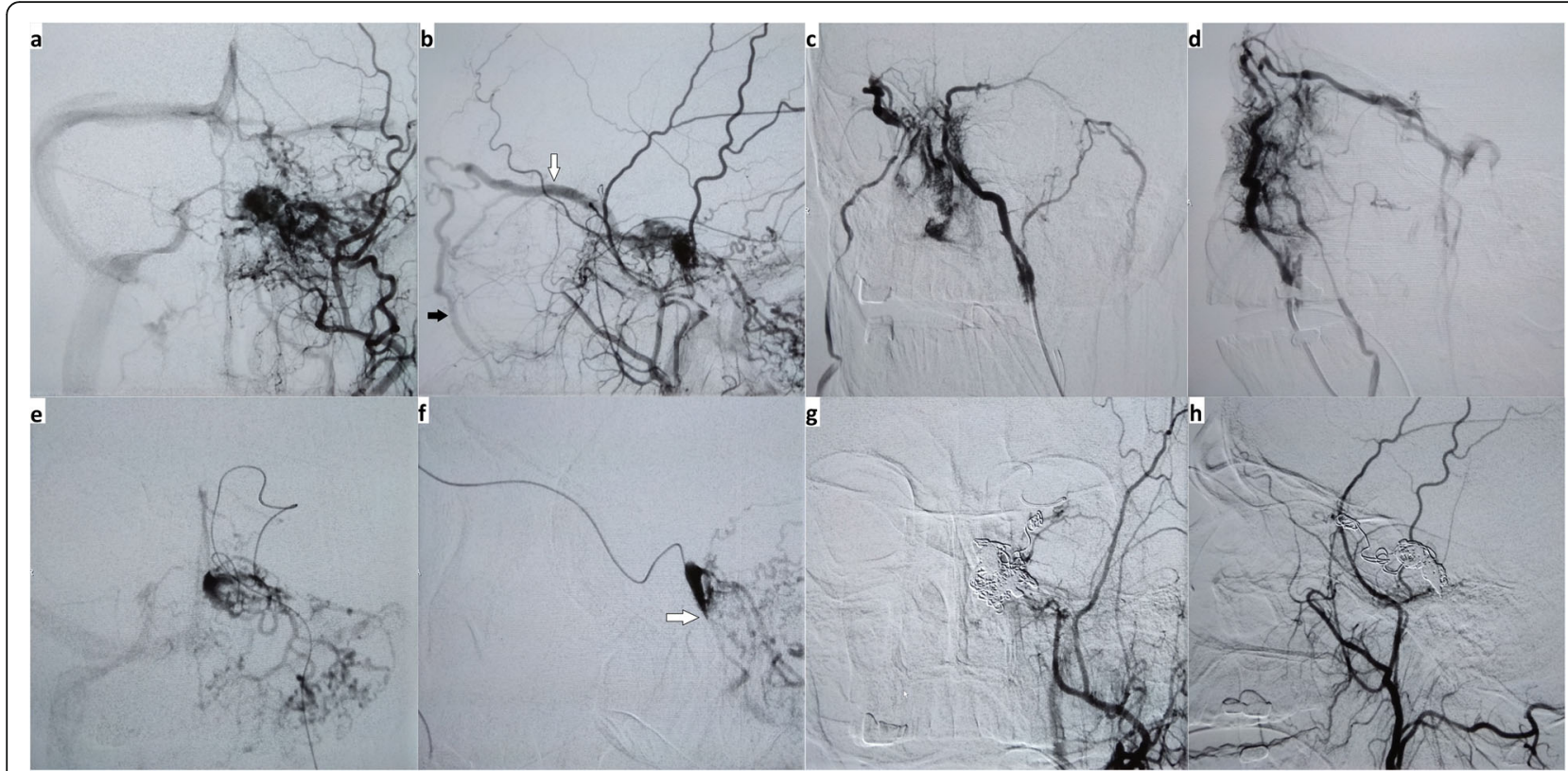

Fig. 5 Left ECA DSA in AP (a) and lateral (b) projections show type C indirect CCF with dilated SOV (white arrow) and facial vein (black arrow). DSA images in oblique (c) and lateral (d) projections show percutaneous puncture and selective cannulation of the left facial vein. DSA images in AP (e) and lateral (f) projections show the microcatheter tip in left cavernous sinus and occluded left IPS (arrow in f). Post coiling DSA in AP (g) and lateral (h) projections show complete embolization of the fistula with coil mass in the left cavernous sinus and adjacent segment of SOV

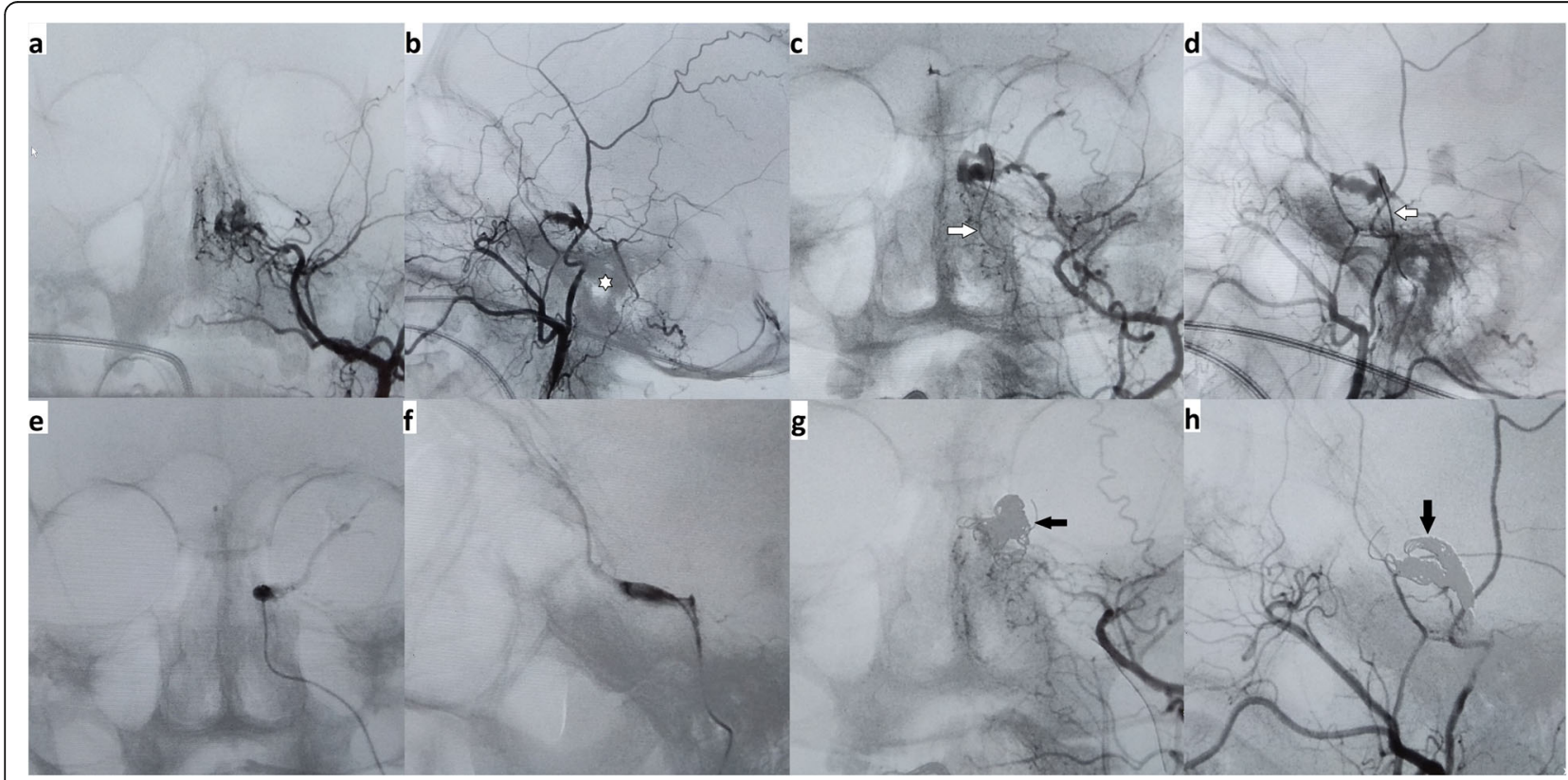

Fig. 6 Left ECA DSA in AP (a) and lateral (b) projections show type C indirect CCF with occluded left IPS (asterisk in b). DSA in AP (c) and lateral (d) projections show successfully recanalized IPS with the microcatheter (white arrow) in place. DSA in AP (e) and lateral (f) projections show tip of the microcatheter lying within the cavernous sinus. Post coiling DSA in AP (g) and lateral (h) projections show coil mass (black arrow) in the cavernous sinus and complete embolization of the fistula 
inferior petro-clival veins to embolize the dural CCF [19, $20]$. In one of our cases, we successfully recanalized the occluded IPS by the microwire to reach the cavernous sinus. Utmost care has to be exercised while trying to recanalize the occluded IPS, as there is always a potential risk of perforation on aggressive attempts leading to subarachnoid or subdural haemorrhage (SDH). The chances of successful recanalization of the IPS are more when duration of illness is less. In chronic cases where the occlusion is organized and fibrosis has taken place, it is not possible and also not advised to attempt for IPS recanalization due to increased risk of complications in the form of SDH $[9,21]$. In one other case where we could not recanalize IPS, we approached the cavernous sinus through USG-guided direct puncture of the facial vein.

Trans-arterial access is taken when no suitable venous route is available and necessitates super-selective cannulation and embolization of ECA branches supplying the CCF $[3,7,13]$. Since the ICA branches to the fistula are usually too small to be selectively cannulated and there is also risk of migration of embolizing agents into the critical vessels supplying intracranial brain parenchyma, they are generally never embolized through arterial route. Thus, with a trans-arterial access, type C CCF may be treated in a single session; however, type D CCF may show residual filling of the fistula from tiny ICA branches. In these cases, repeat embolization is needed or manual compression therapy is advised to the patient and the patient is kept under follow-up. Since the ICA feeders to the fistula are small calibre arteries, there is a high chance of their occlusion by manual compression therapy on follow-up. We had to perform repeat embolization in two type D cases in our series where trans-arterial access was taken. All type D cases, treated with trans-arterial route, were advised and educated for manual compression therapy and all of them showed resolution of symptoms on follow-up.

Various embolizing agents are available including coils, poly-vinyl alcohol (PVA) particles and liquid agents like n-butyl cyanoacrylate (n-BCA - glue) and ethylene vinyl alcohol $(E V O H)$ copolymers. Coils are preferred when the fistula site is accessed by transvenous route for their ease of use and excellent control during deployment [3, $4,9,10]$. Initially, we were using detachable coils for transvenous embolization of indirect CCF. Later, we realized that fibred coils can be used safely in place of detachable coils without compromising the efficacy and outcome of the treatment. We also observed that increased thrombogenicity of fibred coils helps in achieving complete embolization of the indirect CCF in a single session. Similar observations were made by several authors while performing endovascular embolization with fibred coils. More thrombogenic fibred coils ensures better occlusion of the fistula, decreases the chances of recanalization, and helps in achieving complete embolization besides significantly reducing overall cost of the treatment $[2,7,22]$. Slight modification in the approach is required like use of large diameter microcatheter (at least 0.021 " internal diameter) for selective canulation of the IPS and optimum positioning of catheter tip in the cavernous sinus. We performed embolization using fibred coils in ten cases and achieved complete embolization of the indirect CCF in a single session. This helped us in significantly reducing the cost of the treatment.

PVA particles are preferred for embolizing small ECA branches supplying the fistula. With the advances in endovascular hardware, complete embolization of the dural CCF can be achieved even through trans-arterial route by using the liquid embolic agents like ethylene vinyl alcohol copolymers (EVOH, Onyx, Medtronics, USA) or similar materials. The liquid embolic agents should be used with caution while embolizing middle meningeal artery (MMA) supplying the fistula near the foramen spinosum, as there is a high risk of inadvertent embolization of cranial nerve vasa nervosa leading to facial nerve palsy [23]. Moreover, sometimes, a long compliant balloon needs to be kept in cavernous ICA to prevent reflux of liquid embolic agent into the ICA through tiny dural feeders. All these techniques need proper training and expertise to master and have been described in literature for embolization of dural fistula $[4,9,10,16,21]$.

\section{Conclusion}

Indirect or dural CCFs are important cause of ocular symptoms leading to significant morbidity to the patient and may lead to even vision loss if not managed properly. Endovascular embolization is the treatment of choice. Transvenous access through the IPS is preferred approach; however, in cases where IPS is occluded, other routes are explored to access the involved cavernous sinus. Use of fibred coils for indirect CCF embolization is safe and effective and significantly reduces cost of the treatment.

\section{Abbreviations \\ CCF: Carotid-cavernous fistula; ICA: Internal carotid artery; ECA: External carotid artery; DSA: Digital subtraction angiography; IPS: Inferior petrosal sinus; USG: Ultrasound; CECT: Contrast-enhanced computed tomography; MRI: Magnetic resonance imaging; EVOH: Ethylene vinyl alcohol; PVA: Poly- vinyl alcohol}

\section{Acknowledgements}

Nil.

Availability of data and material

All data generated or analysed during this study are included in this published article [and its supplementary information files] and retrieved from the departmental and hospital records. 


\section{Authors' contributions}

The authors have read and approved the manuscript. Concepts: SNP, VK, VS*, RVP, KS. Design: SNP, VK, VS*, RVP, KS. Definition of intellectual content: APS, VK, KS. Literature search: SNP, APS, RVP. Data acquisition: SNP, VK, VS*, RVP, KS. Data analysis: SNP, VS*, RVP. Statistical analysis: APS, RVP, KS. Manuscript preparation: SNP, VS*, RVP. Manuscript editing: SNP, VK, VS*, RVP. Manuscript review: SNP, APS, VK, VS*, RVP, KS. Guarantor: VS*

\section{Funding}

Nil.

\section{Declarations}

\section{Ethics approval and consent to participate}

Ethical approval is not required for retrospective analysis, consent obtained from patients and participants.

\section{Consent for publication}

Obtained from patients and participants.

\section{Competing interests}

The authors declare that they have no competing interests.

\section{Author details}

'Department of Radiodiagnosis, Sanjay Gandhi Post Graduate Institute of Medical Sciences, Lucknow, India. ²Department of Ophthalmology, Sanjay Gandhi Postgraduate Institute of Medical Sciences, Lucknow, India. ${ }^{3}$ Department of Radiology, Apollomedics Super Speciality Hospitals, Lucknow, India.

Received: 29 April 2021 Accepted: 13 June 2021

Published online: 22 June 2021

\section{References}

1. Barrow DL, Spector RH, Braun IF, Landman JA, Tindall SC, Tindall GT (1985) Classification and treatment of spontaneous carotid-cavernous sinus fistulas. J Neurosurg 62(2):248-256. https://doi.org/10.3171/jns.1985.62.2.0248

2. Prasad SN, Singh V, Boruah DK, Phadke RV, Sharma K, Kannaujia V (2020) Endovascular management of direct carotid-cavernous fistula: evolution of cost effective sandwich technique. J Neurosci Rural Pract 11(4):558-564. https://doi.org/10.1055/s-0040-1714447

3. Korkmazer B, Kocak B, Tureci E, Islak C, Kocer N, Kizilkilic O (2013) Endovascular treatment of carotid cavernous sinus fistula: a systematic review. World J Radiol 5(4):143-155. https://doi.org/10.4329/wjr.v5.i4.143

4. de Castro-Afonso LH, Trivelato FP, Rezende MT, Ulhôa AC, Nakiri GS, Monsignore LM, Colli BO, Velasco-e-Cruz AA, Abud DG (2018) Transvenous embolization of dural carotid cavernous fistulas: the role of liquid embolic agents in association with coils on patient outcomes. J NeurointervSurg 10(5):461-462. https://doi.org/10.1136/neurintsurg-2017-013318

5. Yoshida K, Melake M, Oishi H, Yamamoto M, Arai H (2010) Transvenous embolization of dural carotid cavernous fistulas: a series of 44 consecutive patients. AJNR Am J Neuroradiol 31(4):651-655. https://doi.org/10.3174/a jnr.A1882

6. Griauzde J, Gemmete JJ, Pandey AS, Chaudhary N (2017) Dural carotid cavernous fistulas: endovascular treatment and assessment of the correlation between clinical symptoms and the Cognard classification system. J NeurointervSurg 9(6):583-586. https://doi.org/10.1136/ neurintsurg-2016-012418

7. Henderson AD, Miller NR (2018) Carotid-cavernous fistula: current concepts in aetiology, investigation, and management. Eye 32(2):164-172. https://doi. org/10.1038/eye.2017.240

8. Phadke RV, Parihar A, Behari S, Sharma K (2006) Localized congestive venous encephalopathy associated with cavernous dural arteriovenous malformation. Am J Neuroradiol 27(6):1315-1317

9. Baharvahdat H, Shabestari MM, Zabihyan S, Etemadresaei H, Blanc R, Piotin M (2020) Updates in the management of cranial dural arteriovenous fistula. Stroke VascNeurol 5(1):50-58. https://doi.org/10.1136/svn-2019-000269

10. Pashapour A, Mohammadian R, Salehpour F, Sharifipour E, Mansourizade R, Mahdavifard A, Salehi M, Mirzaii F, Sariaslani P, Ardalani GF, Davaraltafi GF (2014) Long-term endovascular treatment outcome of 46 patients with cavernous sinus dural arteriovenous fistulas presenting with ophthalmic symptoms: a non-controlled trial with clinical and angiographic follow-up Neuroradiol J 27(4):461-470. https://doi.org/10.15274/NRJ-2014-10079

11. Park KH, Park JS, Koh EJ, Lee JM (2019) Gamma knife radiosurgery as an alternative treatment of Barrow type B carotid cavernous fistulas: a case report. Medicine 98:15803-15806

12. Wang GC, Chen KP, Chiu TL, Su CF (2017) Treating intracranial dural arteriovenous fistulas with gamma knife radiosurgery: a single-center experience. Tzu Chi Med J 29:18-23

13. Hou K, Li G, Luan T, Xu K, Yu J (2020) Endovascular treatment of the cavernous sinus dural arteriovenous fistula: current status and considerations. Int J Med Sci 17(8):1121-1130. https://doi.org/10.7150/ijms.4 5210

14. Biondi A, Milea D, Cognard C, Ricciardi GK, Bonneville F, van Effenterre R (2003) Cavernous sinus dural fistulae treated by transvenous approach through the facial vein: report of seven cases and review of the literature. AJNR Am J Neuroradiol 24(6):1240-1246

15. Alexandre AM, Visconti E, Lozupone E, D'Argento F, Pedicelli A (2017) Embolization of dural arteriovenous fistula of the cavernous sinus through percutaneous ultrasound-guided puncture of the facial vein. World Neurosurg 99:13-20

16. Wenderoth J (2017) Novel approaches to access and treatment of cavernous sinus dural arteriovenous fistula (CS-DAVF): case series and review of the literature. J NeurointervSurg 9(3):290-296. https://doi.org/1 0.1136/neurintsurg-2016-012742

17. Castro-Afonso LH, Trivelato FP, Rezende MT, Ulhôa AC, Nakiri GS, Monsignore LM et al (2019) The routes for embolization of dural carotid cavernous fistulas when the endovascular approach is indicated as a firstline strategy. IntervNeuroradiol 25:66-70

18. Dye J, Duckwiler G, Gonzalez N, Kaneko N, Goldberg R, Rootman D, Jahan R, Tateshima S, Szeder V (2020) Endovascular approaches to the cavernous sinus in the setting of dural arteriovenous fistula. Brain Sci 10(8):554-569. https://doi.org/10.3390/brainsci10080554

19. Mounayer C, Piotin M, Spelle L, Moret J (2002) Superior petrosal sinus catheterization for transvenous embolization of a dural carotid cavernous sinus fistula. AJNR Am J Neuroradiol 23(7):1153-1155

20. Kurata A, Suzuki S, Iwamoto K, Nakahara K, Inukai M, Niki J, Satou K, Yamada M, Fujii K, Kan S, Katsuta T (2012) A new transvenous approach to the carotid-cavernous sinus via the inferior petrooccipital vein. J Neurosurg 116(3):581-587. https://doi.org/10.3171/2011.4.JNS102155

21. Baharvahdat $H$, Shabestari MM, Zabihyan $S$, Etemadresaei $H$, Blanc R, Piotin M (2014) Transvenous embolization of a carotid cavernous fistula complicated by a hematoma at the tentorial edge. IntervNeuroradiol 20: 301-303

22. Liebig T, Henkes H, Fischer S, Weber W, Miloslavski E, Mariushi W, Brew S, Kühne D (2004 Mar) Fibered electrolytically detachable platinum coils used for the endovascular treatment of intracranial aneurysms: initial experiences and mid-term results in 474 aneurysms. Interv Neuroradiol 10(1):5-26. https://doi.org/10.1177/159101990401000101

23. Chen J, Crane B, Niparko J, Gandhi D (2012) Direct intraoperative confirmation of penetration of ethylene vinyl alcohol copolymer (Onyx) into the vasa nervosa of the facial nerve. J NeurointervSurg 4(6):435-437. https:// doi.org/10.1136/neurintsurg-2011-010116

\section{Publisher's Note}

Springer Nature remains neutral with regard to jurisdictional claims in published maps and institutional affiliations. 